\title{
Role of Diffusion-Weighted Magnetic Resonance Imaging (DWMRI) in Assessment of Primary Penile Tumor Characteristics and Its Correlations With Inguinal Lymph Node Metastasis: A Prospective Study
}

\author{
Sasanka Kumar Barua ${ }^{a}$, Pranab K. Kaman a, Saumar Jyoti Baruahª, Rajeev T. Pa, \\ Puskal K. Bagchi ${ }^{a}$, Debanga Sarma ${ }^{\text {a }}$, Yashasvi Singha, b
}

\begin{abstract}
Background: Penile cancer is a rare malignancy. The extent of lymph node (LN) metastasis is the most important prognostic factor in penile cancer. However, preoperative prediction of LN involvement in clinically non-palpable LN is still a challenge. In absence of a reliable biomarker, attempts are being made to validate imaging characteristics as a predictive tool. The aim of the present study is to assess the primary penile tumor characteristics with diffusion-weighted magnetic resonance imaging (DWMRI) and its correlations with inguinal LN status and tumor positivity in LN dissection specimen within normal sized LNs.
\end{abstract}

Methods: Twenty-six patients with carcinoma penis underwent DWMRI of penis and pelvis. The apparent diffusion coefficient (ADC) values of primary tumor were compared with histological characteristics. Inclusion criteria encompassed all cases of clinically nonpalpable inguinal LN and normal sized LN on imaging. All palpable inguinal nodes with pelvic lymphadenopathies were excluded from this study.

Results: The primary tumor ADC ranged from $0.65 \times 10^{-3}-1.2 \times$ $10^{-3} \mathrm{~mm}^{2} / \mathrm{s}$ (mean: $0.87 \times 10^{-3} \pm 0.11 \times 10^{-3} \mathrm{~mm}^{2} / \mathrm{s}$ ). In pT1 and pT3 tumors, mean $\mathrm{ADC}$ values were $0.86 \times 10^{-3} \pm 0.10 \times 10^{-3}$ and 0.81 $\times 10^{3} \pm 0.09 \times 10^{3} \mathrm{~mm}^{2} / \mathrm{s}$, respectively. The mean $\mathrm{ADC}$ values for grade 1 , grade 2 and grade 3 were $0.89 \times 10^{-3}, 0.82 \times 10^{-3}$ and $0.80 \times$ $10^{-3} \mathrm{~mm}^{2} / \mathrm{s}$, respectively. The ADC value of $<0.95 \times 10^{-3} \mathrm{~mm}^{2} / \mathrm{s}$ was positively correlated with pathological $\mathrm{LN}$ presence within normal sized LN. With mean ADC value of $0.87 \times 10^{-3} \pm 0.11 \times 10^{-3} \mathrm{~mm}^{2} / \mathrm{s}$, sensitivity and positive predictive values for primary penile cancer were $100 \%$ and $84.61 \%$, respectively. The mean ADC value for high-

Manuscript submitted August 25, 2018, accepted September 24, 2018

aDepartment of Urology, Gauhati Medical College Hospital, Guwahati, Assam, India

${ }^{b}$ Corresponding Author: Yashasvi Singh, Department of Urology, 3rd Floor, GMCH Complex, GMC Hostel Road, Bhangagarh, Guwahati 781032, Assam, India. Email: yashasvisingh075@gmail.com

doi: https://doi.org/10.14740/wjon1138w er-grade and -stage tumor was low. The sensitivity and specificity of predicting LN metastasis by DWMRI were $87.22 \%$ and $80.90 \%$, respectively.

Conclusion: ADC value of primary tumor can help in prediction of LN metastasis in carcinoma penis with clinically and radiologically normal groin.

Keywords: Carcinoma penis; Lymph node; DWMRI; ADC value

\section{Introduction}

Penile cancer is a rare entity which accounts for $0.4-0.6 \%$ of all malignant neoplasms among men [1]. Its expanse is more common in a developing country which is signified by the fact that it accounts for about $10 \%$ of all malignant disease burdens [2]. The presence and extent of lymph node (LN) metastasis is the most important prognostic factor in penile cancer which can be assessed by clinical examination, ultrasonography, computed tomography (CT), magnetic resonance imaging (MRI) or fluoro-deoxyglucose positron emission tomography. Diffusion-weighted MRI (DWMRI) is a functional imaging technique that depends upon Brownian motion of water which can calculate apparent diffusion coefficient (ADC) of tissue. ADC values provide functional information that distinguishes benign LNs from metastatic LNs even in similar size LNs reported as normal in radiological studies.

\section{Aim}

The aim of the study was to assess the primary penile tumor characteristics (size, site, invasion into tunica, corpus spongiosa, corpus cavernosa and urethra) with DWMRI and its correlations with normal sized inguinal LN (radiologically and clinically) characteristics such as size, shape, location, number, and internal nodal architecture and tumor positivity in LN dissection specimen. 
Table 1. ADC Value and Stage of Primary Tumor

\begin{tabular}{|c|c|c|c|c|c|c|c|}
\hline \multirow{2}{*}{ ADC value $\left(\times 10^{-3} \mathrm{~mm}^{2} / \mathrm{s}\right)$} & \multicolumn{3}{|c|}{ Histopathology (pT) } & \multirow{2}{*}{ Chi-square test variable } & \multirow{2}{*}{ P value } & \multirow{2}{*}{ Pearson's $R$ correlation coefficient } & \multirow{2}{*}{ P value } \\
\hline & T1 & $\mathbf{T 2}$ & T3 & & & & \\
\hline $0.65-0.75$ & 0 & 0 & 2 & 17.247 & 0.045 & -0.496 & 0.001 \\
\hline $0.86-0.95$ & 4 & 4 & 4 & & & & \\
\hline $0.95-1.2$ & 1 & 3 & 1 & & & & \\
\hline
\end{tabular}

\section{Patients and Methods}

This prospective study was conducted between March 2016 and December 2017 in the Department of Urology, GMCH Guwahati after obtaining clearance from the institutional ethical committee. A written consent was taken from all patients. The inclusion criteria comprised of all carcinoma penis with non-palpable inguinal LN and normal sized LN on imaging. The exclusion criteria included all palpable inguinal LN and pelvic lymphadenopathy. All patients with carcinoma penis were investigated with DWMRI of primary penile lesion, inguinal region and pelvis. All patients were investigated in flaccid state. After evaluation, all patients were treated with penectomy (partial/total) and inguinal LN dissection (unilateral/bilateral) with or without pelvic LN dissection (unilateral/ bilateral). Any correlations between the findings of DWMRI of primary lesion and histopathological findings of primary tumor and dissected LNs were analyzed.

MRI was performed using a $1.5 \mathrm{~T}$ superconductive magnet MRI system with maximum gradient amplitude of 40 $\mathrm{mT} / \mathrm{m}$ and a maximum slew rate of $135 \mathrm{mT} / \mathrm{m} / \mathrm{s}$ along with a 16-channel-body array coil. For functional evaluation, DWMRI was performed in the transverse plane, with the following parameters: section thickness of $4 \mathrm{~mm}$, intersection gap of $0.8 \mathrm{~mm}$, three $\mathrm{b}$ values $\left(0,400\right.$ and $\left.1,000 \mathrm{~s} / \mathrm{mm}^{2}\right)$ in three orthogonal directions with eight averages, 5,570/62, $975 \mathrm{~Hz} /$ pixel bandwidth, $300 \times 300 \mathrm{~mm}^{2}$ field of view and $256 \times 256$ matrix. Presence of the tumor was defined as high signal intensity on diffusion-weighted imaging (DWI). The ADC value of the tumor and LNs was calculated in a circular region of interest for quantitative analysis. The correlation between variables was assessed using Pearson's R coefficient and the test of significance was assessed with Chi-square, $t$-test, oneand two-way ANOVA. A P value of $<0.05$ was considered significant. All these statistical analyses were done using SPSS version 21.0.

\section{Results}

This study included a total of 26 patients. Age groups ranged from 25 to 76 years (mean: $42.5 \pm 12.29$ years). Twelve $(46.15 \%)$ patients presented with duration of $>12$ months. Phimosis was associated with 17 (65.38\%) patients. The most common site of involvement was distal third of penile shaft. ADC value of primary tumor ranged between $0.65 \times 10^{-3}$ and $1.20 \times 10^{-3} \mathrm{~mm}^{2} / \mathrm{s}$ (mean: $0.87 \times 10^{-3} \pm 0.11 \times 10^{-3} \mathrm{~mm}^{2} / \mathrm{s}, 95 \%$ confidence interval (CI): 0.827 - 0.918). The pT1, pT2 and pT3 stages were found in $6(23.07 \%), 9(34.63 \%)$ and $11(42.30 \%)$ patients respectively (Table 1 ).

The mean ADC values of pT1 and pT3 stage were $0.86 \times$ $10^{-3} \pm 0.10 \times 10^{-3} \mathrm{~mm}^{2} / \mathrm{s}(95 \% \mathrm{CI}: 0.77-0.95)$ and $0.81 \times 10^{-3}$ $\pm 0.09 \times 10^{-3} \mathrm{~mm}^{2} / \mathrm{s}(95 \% \mathrm{CI}: 0.75-0.80)$, respectively $(\mathrm{P}=$ $0.045)$.

The numbers of patients in pathological grades 1, 2 and 3 were $18(69.23 \%), 7(26.92 \%)$ and 1 (3.85\%), respectively, and their mean ADC values were $0.89 \times 10^{-3}, 0.82 \times 10^{-3}$ and $0.80 \times 10^{-3} \mathrm{~mm}^{2} / \mathrm{s}$, respectively (Table 2 ).

When cutoff value of ADC was $<0.95 \times 10^{-3} \mathrm{~mm}^{2} / \mathrm{s}$, the sensitivity and positive predictive value were $100 \%$ and $84.61 \%$, respectively.

The total number of LNs detected on DWMRI was 68 (34 each on both right and left sides) with mean size of $1.2 \times$ $0.8 \mathrm{~cm}$. Round and oval shaped LNs were seen in $76.47 \%$ and $23.53 \%$ cases, respectively. Heterogeneous and homogeneous LNs were observed in $58.82 \%$ and $41.18 \%$ cases, respectively.

On the right side, numbers of LNs extracted during surgery and tumor positivity (histopathological examination (HPE))

Table 2. ADC Value and Histological Grade of Primary tumor

\begin{tabular}{|c|c|c|c|c|c|c|c|}
\hline \multirow{2}{*}{ ADC value $\left(\times 10^{-3} \mathrm{~mm}^{2} / \mathrm{s}\right)$} & \multicolumn{3}{|c|}{ Grade } & \multirow{2}{*}{ Chi-square test variable } & \multirow{2}{*}{ P value } & \multirow{2}{*}{ Pearson's $\mathbf{R}$ correlation coefficient } & \multirow{2}{*}{ P value } \\
\hline & G1 & G2 & G3 & & & & \\
\hline $0.65-0.75$ & 2 & 1 & 0 & 13.176 & 0.040 & -0.525 & 0.005 \\
\hline $0.76-0.85$ & 4 & 3 & 1 & & & & \\
\hline $0.86-0.95$ & 8 & 3 & 0 & & & & \\
\hline $0.95-1.2$ & 4 & 0 & 0 & & & & \\
\hline Total & 18 & 7 & 1 & & & & \\
\hline
\end{tabular}


Table 3. ADC Value and Histopathology of LN (Right Side)

\begin{tabular}{lllllll}
\hline ADC value $\left(\times \mathbf{1 0}^{-\mathbf{3}} \mathbf{~ m m}^{\mathbf{2}} \mathbf{s}\right)$ & No. & HPE $(+\mathbf{v e})$ & $t$-test variable & P value & Pearson's R correlation coefficient & P value \\
\hline $0.65-0.75$ & 9 & 9 & 4.57 & 0.001 & 0.457 \\
$0.76-0.85$ & 5 & 5 & & & \\
$0.86-0.95$ & 9 & 9 & & & \\
$0.95-1.2$ & 11 & 4 & & & \\
Total & 34 & 27 & & & \\
\hline
\end{tabular}

Table 4. ADC Value and Histopathology of LN (Left Side)

\begin{tabular}{llllll}
\hline ADC value $\left(\times \mathbf{1 0}^{-\mathbf{3}}{\left.\mathbf{~} \mathbf{m}^{\mathbf{2}} \mathbf{s}\right)}^{\text {No. }}\right.$ & HPE $(+\mathbf{v e})$ & $t$-test variable & P value & Pearson's R correlation coefficient & P value \\
\hline $0.65-0.75$ & 10 & 9 & 5.249 & 0.001 & 0.390 \\
$0.76-0.85$ & 7 & 7 & & & \\
$0.86-0.95$ & 7 & 7 & & & \\
$0.95-1.2$ & 10 & 1 & & & \\
Total & 34 & 24 & & & \\
\hline
\end{tabular}

were 34 and $27(79.41 \%)$, respectively, with ADC value ranging between $0.65 \times 10^{-3}$ and $1.2 \times 10^{-3} \mathrm{~mm}^{2} / \mathrm{s}$ (Table 3 ). Nevertheless, when ADC values were fixed to $<0.95 \times 10^{-3} \mathrm{~mm}^{2} / \mathrm{s}$, total number of positive biopsies was only $23(\mathrm{P}=0.001)$.

On the left side, numbers of LNs and tumor positivity were 34 and $24(70.58 \%)$, respectively (Table 4$)$, but when ADC values were fixed to $<0.95 \times 10^{-3} \mathrm{~mm}^{2} / \mathrm{s}$, number of tumor positivity on histology was $23(\mathrm{P}=0.001)$.

When cutoff value of ADC was $<0.95 \times 10^{-3} \mathrm{~mm}^{2} / \mathrm{s}$, its sensitivity, specificity, positive predictive value and negative predictive value of ADC values were $87.22 \%, 80.90 \%$, $91.10 \%$ and $73.86 \%$, respectively $(\mathrm{P}=0.001)$. DWI showed an area under the receiver operating characteristic (ROC) curve (AUC) of 0.934 (standard error (SE): $0.042 ; 95 \%$ CI: 0.851 - 1) on the right side (Fig. 1a), whereas it showed an AUC of
0.885 (SE: $0.091 ; 95 \%$ CI: 0.706 - 1) on the left side (Fig. 1b).

\section{Discussion}

Penile cancer is an aggressive and rare cancer and it usually affects older men. Gursel et al [3] along with Derrick and his team [4] showed that mean ages of occurrence were 58 and 55 years, respectively, though the tumor is not unusual in younger men. According to a study conducted by Dean and his team [5], 22\% of patients were younger than 40 years and $7 \%$ were younger than 30 years. In our study, age ranged from 25 to 76 years (mean: $42.5 \pm 12.29$ years).

Neonatal circumcision has been authentically established as a prophylactic measure that virtually eliminates the occur-

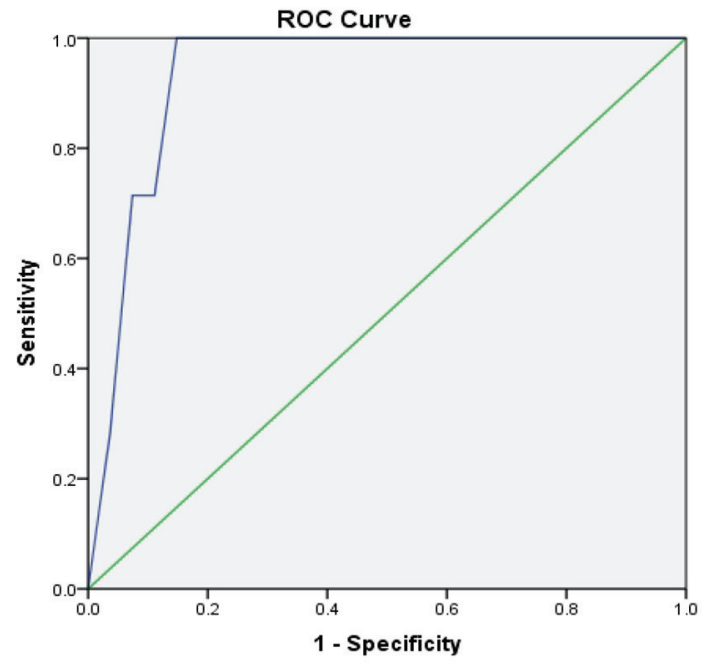

Diagonal segments are produced by ties.

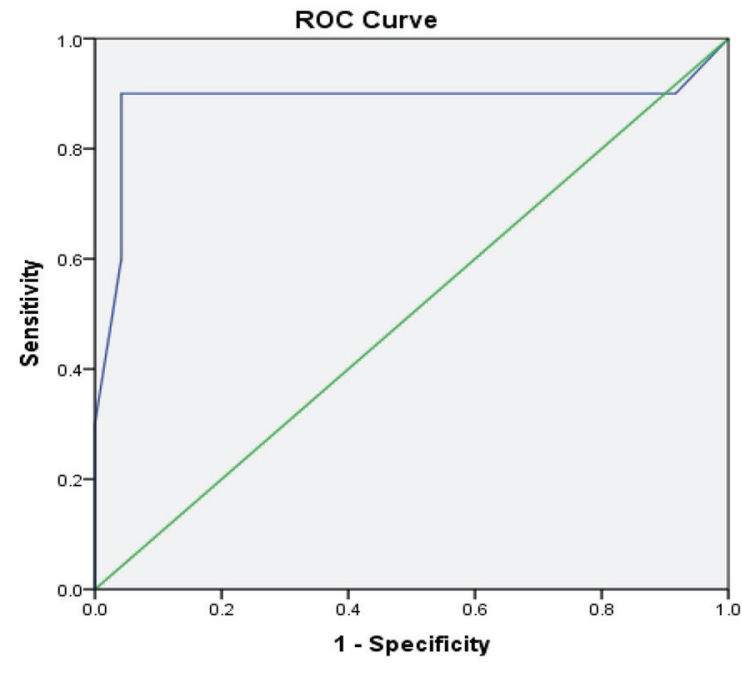

Diagonal segments are produced by ties.

Figure 1. (a) ROC curve on the right side; (b) ROC curve on the left side. 
rence of penile carcinoma. Phimosis is present in $25-75 \%$ of patients of carcinoma of penis [6]. In our study, $17(65.38 \%)$ patients presented with phimosis.

In patients with penile cancer, both the primary tumor and the inguinal LNs are readily assessed by palpation. However, Horenblas and his team [7] found that physical examination incorrectly established the actual pathological stage in $26 \%$ of cases, with under and over staging of $10 \%$ and $16 \%$, respectively. To bridge this gap of discrepancy between physical examination and tumor positivity in inguinal nodes, several studies are being carried out with ultrasonography and recently with MRI [8-10].

DWMRI is widely used in almost all disciplines for tumor detection, characterization and the evaluation of treatment response in patients with cancer [11]. Recent studies have described the usefulness of DWI for detecting malignant tumors of the liver, renal, prostate, colorectal and pancreas [12, 13]. DWI is a functional imaging technique that reflects changes in proton mobility caused by the alteration of tissue cellularity and the integrity of the cellular membrane, tortuosity of extracellular space and viscosity of fluids due to pathological processes [14-16]. The gradients are characterized by their $b$ values, which express the amount of diffusion weighting [17, 18]. By performing DWI using different $b$ values, quantitative analysis, namely, the calculation ADC values, is possible and the ADC values can be displayed as a parametric map (ADC map) [11]. It is observed that malignant tissues have higher signal intensity on DWI and lower ADC value.

Kobayashi et al [19] reported sensitivity rates $>90 \%$ for DWI for detecting bladder cancer with median ADC value of $0.86 \times 10^{-3} \mathrm{~mm}^{2} / \mathrm{s}$. Matsuki et al. [20] were able to visualize on DWI all 17 bladder cancers in 15 patients with sensitivity and positive predictive values of $100 \%$. The mean ADC value of tumor was $1.18 \times 10^{-3} \mathrm{~mm}^{2} / \mathrm{s}$, which was significantly lower than those of surrounding structures. In our study, mean ADC value of primary penile tumor was $0.87 \times 10^{-3} \pm 0.11 \times$ $10^{-3} \mathrm{~mm}^{2} / \mathrm{s}$. The sensitivity and positive predictive value for detected primary penile cancer were $100 \%$ and $84.61 \%$, respectively. Our observation is similar to the study conducted by aforementioned authors.

Takeuchi et al [21] recently reported that the mean ADC value of grade 3 bladder cancer was significantly lower than those of grade 1 and grade 2 tumors. In our study, the mean ADC values of grade 3 , grade 2 and grade 1 penile cancer were $0.80 \times 10^{-3}, 0.82 \times 10^{-3}$ and $0.89 \times 10^{-3} \mathrm{~mm}^{2} / \mathrm{s}$, respectively $(\mathrm{P}$ $=0.040)$, thus validating the abovementioned findings. Similarly, Kobayashi et al [19] reported that mean ADC values was lower in high-grade and high-stage tumors. In our study, mean $\mathrm{ADC}$ values of T3 and T1 stages were $0.817 \times 10^{-3} \pm 0.09 \times$ $10^{-3}$ and $0.86 \times 10^{-3} \pm 0.10 \times 10^{-3} \mathrm{~mm}^{2} / \mathrm{s}$, respectively, which indicated that higher $\mathrm{pT}$ stage tumor has lower ADC value $(\mathrm{P}$ $=0.045$ ).

The number of LNs detected with DWMRI preoperatively in our study was 68 (34 each on both right and left sides). The numbers of LNs positive on inguinal LN dissection (ILND) on right and left sides were $27(79.41 \%)$ and $24(70.59 \%)$, respectively, with ADC in the range of $0.65 \times 10^{-3}-1.2 \times 10^{-3} \mathrm{~mm}^{2} / \mathrm{s}$ (mean ADC: $0.87 \times 10^{-3} \mathrm{~mm}^{2} / \mathrm{s}$ ). However, when the ADC value was fixed to $<0.95 \times 10^{-3} \mathrm{~mm}^{2} / \mathrm{s}$, numbers of positive
Table 5. Sizes of LNs as reported in MRI

\begin{tabular}{|c|c|c|c|}
\hline \multicolumn{4}{|c|}{ LN(sz) } \\
\hline $\operatorname{Rt}(\mathrm{L})(\mathrm{cm})$ & $\operatorname{Rt}(B)(\mathrm{cm})$ & $\mathrm{Lt}(\mathrm{L})(\mathrm{cm})$ & $\mathrm{Lt}(\mathrm{B})(\mathrm{cm})$ \\
\hline 1.42 & 1.06 & 1.4 & 1.1 \\
\hline 1.2 & 1.5 & 1.9 & 1.8 \\
\hline 1.7 & 1.45 & 1.1 & 1 \\
\hline 1.5 & 1.5 & 1.7 & 1.7 \\
\hline 1.1 & 1 & 1.2 & 1.1 \\
\hline 1.7 & 1.1 & 1.5 & 1.2 \\
\hline 1.5 & 2 & 1.4 & 1 \\
\hline 2 & 1.3 & 1.6 & 1.8 \\
\hline 1.6 & 1.7 & 2.1 & 1.3 \\
\hline 1.1 & 1.6 & 1.5 & 1.1 \\
\hline 1.4 & 1.1 & 1.1 & 1 \\
\hline 2 & 1.1 & 1.3 & 1.2 \\
\hline 1.1 & 1.5 & 2.6 & 2.4 \\
\hline 1.6 & 1.2 & 1.5 & 1.1 \\
\hline 1.7 & 1.4 & 1.4 & 1.2 \\
\hline 1.5 & 1.2 & 2.4 & 1.4 \\
\hline 1.2 & 1.1 & 1.5 & 1.1 \\
\hline 1.3 & 1 & 1.7 & 1.3 \\
\hline 1.2 & 1.2 & 2.3 & 1.8 \\
\hline 1.5 & 1.3 & 1.4 & 1.1 \\
\hline 1.4 & 1.8 & 1.7 & 1 \\
\hline 1.2 & 1.1 & 1.1 & 1 \\
\hline 2.2 & 1.3 & 2.1 & 1.7 \\
\hline 1.4 & 1.9 & 2.1 & 1.8 \\
\hline 1.6 & 1.2 & 1.5 & 1 \\
\hline 2.1 & 1.5 & 2.1 & 1.6 \\
\hline
\end{tabular}

histopathology for radiologically normal sized LNs on right and left sides were found to be 23 (100\%) and 23 (95.83\%), respectively $(\mathrm{P}=0.001)$.

Squamous cell carcinoma of the penis metastasizes in a stepwise pattern. Skip metastases have rarely been reported. The clinically node-negative patients present a challenge for additional imaging as approximately $20 \%$ will harbor clinically undetectable metastases.

Lin et al [22] evaluated detection rate of pelvic LN metastasis in patients with cervical cancer on DWI. They further suggested that combination of size and relative ADC values were useful in detecting pelvic LN metastasis in these patients with a sensitivity of $83 \%$.

Kim and his team [23] reported that the ADC values were significantly lower in the metastatic LN than in the non-metastatic LN of cervical cancer patients. They observed sensitivity and specificity to be $87 \%$ and $80 \%$ respectively with ADC value of $0.90 \times 10^{-3} \mathrm{~mm}^{2} / \mathrm{s}$.

In our study, mean ADC value of primary tumor which 
was deemed to harbor metastasis was $0.87 \times 10^{-3} \mathrm{~mm}^{2} / \mathrm{s}$ and sensitivity, specificity, positive predictive value and negative predictive value were $87.22 \%, 80.90 \%, 91.10 \%$ and $73.86 \%$, respectively. Our study has congruent observation with aforementioned authors.

On cross-sectional imaging, normal LNs usually appear homogeneous, oval- or cigar-shaped with well-defined borders (Table 5). According to van den Brekel et al [24] and Imhof et al [25], round-shaped nodes were more likely to harbor metastases. In our study, round-shaped metastatic LNs were found $76.47 \%$ and $64.71 \%$ on right and left sides, respectively. We have not found any significant correlations among these matched variables.

\section{Conclusions}

It is evident from our study that the metastatic LNs in the inguinal region can be precisely predicted by DWMRI by correlating ADC value of primary tumor even when the sizes of LNs are within normal limit. We perceived a positive correlation between ADC values of primary tumor and LN positivity for metastasis even in normal sized LNs. We have not found any significant correlations between the ADC values of primary tumor, internal nodal architecture and shape of LN. This may be due to small sample size in our study. Therefore, further long-term multi-institutional studies with larger sample size are required for its validation.

\section{References}

1. Vatanasapt V, Martin N, Sriplung H, Chindavijak K, Sontipong S, Sriamporn H, Parkin DM, et al. Cancer incidence in Thailand, 1988-1991. Cancer Epidemiol Biomarkers Prev. 1995;4(5):475-483.

2. Bleeker MC, Heideman DA, Snijders PJ, Horenblas S, Dillner J, Meijer CJ. Penile cancer: epidemiology, pathogenesis and prevention. World J Urol. 2009;27(2):141150.

3. Gursel EO, Georgountzos C, Uson AC, Melicow MM, Veenema RJ. Penile cancer. Urology. 1973;1(6):569-578.

4. Derrick FC, Jr., Lynch KM, Jr., Kretkowski RC, Yarbrough WJ. Epidermoid carcinoma of the penis: computer analysis of 87 cases. J Urol. 1973;110(3):303-305.

5. Dean AL Jr. Epithelioma of the penis. J Urol. 1935;33:252283.

6. Pettaway CA, Crook JM, Pagliaro LC. Tumours of the Penis. Wein AJ, editor. Campbell - Walsh Urology, 11th edition. Philadelphia: Elsevier publishers; 2016. p. 847.

7. Horenblas S, Van Tinteren H, Delemarre JF, Moonen LM, Lustig V, Kroger R. Squamous cell carcinoma of the penis: accuracy of tumor, nodes and metastasis classification system, and role of lymphangiography, computerized tomography scan and fine needle aspiration cytology. J Urol. 1991;146(5):1279-1283.

8. Vapnek JM, Hricak H, Carroll PR. Recent advances in imaging studies for staging of penile and urethral carcinoma. Urol Clin North Am. 1992;19(2):257-266.
9. Vossough A, Pretorius ES, Siegelman ES, Ramchandani P, Banner MP. Magnetic resonance imaging of the penis. Abdom Imaging. 2002;27(6):640-659.

10. Hanchanale V, Yeo L, Subedi N, Smith J, Wah T, Harnden $\mathrm{P}$, Bhattarai $\mathrm{S}$, et al. The accuracy of magnetic resonance imaging (MRI) in predicting the invasion of the tunica albuginea and the urethra during the primary staging of penile cancer. BJU Int. 2016;117(3):439-443.

11. Koh DM, Collins DJ. Diffusion-weighted MRI in the body: applications and challenges in oncology. AJR Am J Roentgenol. 2007;188(6):1622-1635.

12. Parikh T, Drew SJ, Lee VS, Wong S, Hecht EM, Babb JS, Taouli B. Focal liver lesion detection and characterization with diffusion-weighted MR imaging: comparison with standard breath-hold T2-weighted imaging. Radiology. 2008;246(3):812-822.

13. Xu PJ, Yan FH, Wang JH, Lin J, Ji Y. Added value of breathhold diffusion-weighted MRI in detection of small hepatocellular carcinoma lesions compared with dynamic contrast-enhanced MRI alone using receiver operating characteristic curve analysis. J Magn Reson Imaging. 2009;29(2):341-349.

14. Koyama T, Togashi K. Functional MR imaging of the female pelvis. J Magn Reson Imaging. 2007;25(6):11011112.

15. Kilickesmez O, Bayramoglu S, Inci E, Cimilli T, Kayhan A. Quantitative diffusion-weighted magnetic resonance imaging of normal and diseased uterine zones. Acta Radiol. 2009;50(3):340-347.

16. Whittaker CS, Coady A, Culver L, Rustin G, Padwick M, Padhani AR. Diffusion-weighted MR imaging of female pelvic tumors: a pictorial review. Radiographics. 2009;29(3):759-774; discussion 774-758.

17. Hoeks CM, Barentsz JO, Hambrock T, Yakar D, Somford DM, Heijmink SW, Scheenen TW, et al. Prostate cancer: multiparametric MR imaging for detection, localization, and staging. Radiology. 2011;261(1):46-66.

18. Hafeez S, Huddart R. Advances in bladder cancer imaging. BMC Med. 2013;11:104.

19. Kobayashi S, Koga F, Yoshida S, Masuda H, Ishii C, Tanaka H, Komai Y, et al. Diagnostic performance of diffusion-weighted magnetic resonance imaging in bladder cancer: potential utility of apparent diffusion coefficient values as a biomarker to predict clinical aggressiveness. Eur Radiol. 2011;21(10):2178-2186.

20. Matsuki M, Inada Y, Tatsugami F, Tanikake M, Narabayashi I, Katsuoka Y. Diffusion-weighted MR imaging for urinary bladder carcinoma: initial results. Eur Radiol. 2007;17(1):201-204.

21. Takeuchi M, Sasaki S, Ito M, Okada S, Takahashi S, Kawai T, Suzuki K, et al. Urinary bladder cancer: diffusion-weighted MR imaging - accuracy for diagnosing $\mathrm{T}$ stage and estimating histologic grade. Radiology. 2009;251(1):112-121.

22. Lin G, Ho KC, Wang JJ, Ng KK, Wai YY, Chen YT, Chang CJ, et al. Detection of lymph node metastasis in cervical and uterine cancers by diffusion-weighted magnetic resonance imaging at 3T. J Magn Reson Imaging. 2008;28(1):128-135. 
23. Kim JK, Kim KA, Park BW, Kim N, Cho KS. Feasibility of diffusion-weighted imaging in the differentiation of metastatic from nonmetastatic lymph nodes: early experience. J Magn Reson Imaging. 2008;28(3):714-719.

24. van den Brekel MW, Stel HV, Castelijns JA, Nauta JJ, van der Waal I, Valk J, Meyer CJ, et al. Cervical lymph node metastasis: assessment of radiologic criteria. Radiology. 1990;177(2):379-384.

25. Imhof $\mathrm{H}$, Czerny $\mathrm{C}$, Dirisamer $\mathrm{A}$. Head and neck imaging with MDCT. Eur J Radiol. 2003;45(Suppl 1):S23-31. 